\title{
The World Journal of Surgery Welcomes Dr. Masato Nagino to the Editorial Board
}

\author{
Julie Ann Sosa ${ }^{1}$
}

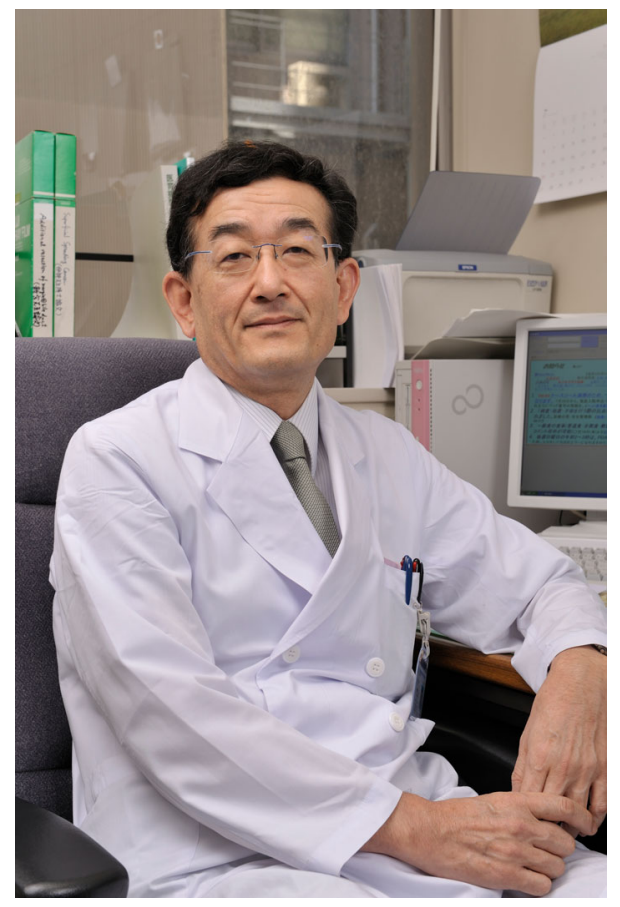

Dr. Masato Nagino was born and raised in Anjo, Aichi Prefecture, Japan. He graduated from Nagoya University Graduate School of Medicine in 1979 and completed his surgical residency training in Yachiyo Hospital in Anjo and Cancer Institute Hospital in Tokyo. He obtained his Ph.D. from Nagoya University in 1989 and joined the faculty as an Assistant Professor. In 2007, he was promoted to the Chairman of the Department of Surgery, Nagoya University. His major interest is in hepatobiliary surgery, especially extended surgery for perihilar cholangiocarcinoma. He has experience with more than 1000 resections of perihilar cholangiocarcinoma. His research has focused on reducing morbidity and mortality of complicated hepatobiliary resections and, in turn, improving patient survival of biliary tract cancers. In 2020, he resigned as the chairman due to retirement age and moved to Aichi Cancer Center. He still continues clinical practice. He has more than 600 publications in many leading journals.

Publisher's Note Springer Nature remains neutral with regard to jurisdictional claims in published maps and institutional affiliations.

Julie Ann Sosa, MD, MA, FACS—Editor in Chief, World Journal of Surgery.

\footnotetext{
Julie Ann Sosa

julie.sosa@ucsf.edu
}

1 San Francisco, USA 